\title{
Thermal performance evaluation of horizontal spiral coil-type ground heat exchangers
}

\author{
Min-Jun kim \\ Jun-Seo Jeon
}

\author{
Seung-Rae Lee \\ Min-Seop Kim
}

\author{
Hwan-Hui Lim
}

\begin{abstract}
Geothermal energy has been widely used over the world instead of fossil fuel for environmental merits. A ground-source beat pump (GSHP) system utilizes a constant ground temperature to absorb heat during winter and to emit beat in summer. The GSHP system can be devieded into a closed type system and an open type system. The closed type system using a horizontal ground heat exchanger (HGHE) is relatively inexpensive and easy to install compared to the other types of systems. Among the types of HGHEs, since a horizontal spiral-coil type GHE has the advantageous arrangement for heat exchange between the heat exchanger and surrounding ground, it is the most effective type of the HGHE in terms of thermal performance. However, the thermal performance of a horizontal spiral-coil type GHE critically depends on its dimension which consists of the radius and pitch of a spiral, and thus it is important to accurately analyze how the radius and pitch affect the thermal performance of the horizontal spiral-coil type GHE. Therefore, this paper investigated the thermal performance of a horizontal spiral-coil type GHE according to its diverse shapes to suggest a beneficial design specification of the horizontal spiral-coil type GHE. In order to evaluate the thermal performance of the heat exchanger, a spiral-coil type HGHE was installed in a steel box of which the size was $5 m \times 1 m \times 1 \mathrm{~m}$ filled with dry Joomunjin standard sand, and a thermal response test (TRT) was conducted for 30 hours continuously. Besides, a numerical analysis was performed for its verification and a parametric study of the horizontal spiral-coil GHE using a numerical program which is based on a finite element method (FEM). As a result, in case that the pitch of the borizontal spiral-coil type GHE was more than 0.6 $m$, there was no more significant benefit in the thermal performance.
\end{abstract}

\section{INTRODUCTION}

Renewable energy has been widely used throughout the world as a substitute for fossil fuels due to its ecological advantages. Geothermal energy, one of the renewable energy types, has no environmental problems, and it can be used at any time regardless of a weather condition. The ground-source heat pump (GSHP) system utilizes a relatively constant ground temperature to discharge heat in summer and to obtain heat in winter for heating and cooling, respectively. The GSHP system can be divided into a closed type system and an open type system. The closed-type system can be vertical or horizontal, depending on the installation method. The vertical system uses vertically installed ground heat exchangers (GHEs) in which circulating fluid flows in the pipe embedded in the ground to a depth of 150 200 m. This system can demand high initial construction costs because of deep boreholes. The horizontal system can be used as an alternative

Min-Jun Kim is a doctor course student, Seung-Rae Lee (srlee@kaist.ac.kr) is a professor of civil and environmental engineering department at KAIST, Jun-Seo Jeon is a post Doctor, Hwan-Hui Lim is a master course student and Min-Seop Kim is a doctor course student there. 
to the vertical system. Since GHEs in the horizontal system are installed at shallow depths of $1 \sim 3 \mathrm{~m}$ parallel to the ground surface, it does not need boring costs which are more expensive than excavation costs in the installation process of the horizontal system. However, despite the huge economic benefits of the horizontal system, it is not widely used in comparison with the vertical system due to a great deal of required land space in the HGHEs. As a solution to this problem, a horizontal spiral configuration can be optimized to minimize the installation area of GHE.

While previous studies regarding a horizontal spiral-coil type GHE showed its better efficient performance [1, 2], there have not been yet studies considering thermal performance according to a pitch variation. A coil pitch denotes the distance between the center of spiral rings, and it is a critical factor to determine the thermal performance of GHE. As shown in Fig 1, if the coil pitch is too small, the thermal performance efficiency decreases due to thermal interference while the large coil pitch is not advantageous for heat exchange with surrounding ground. Accordingly, it is important to decide an advantageous pitch in the design of a horizontal spiral-coil type GHE.

Thus, the thermal performance of a horizontal spiral-coil type GHE according to pitch variation through a numerical analysis was carried out in order to suggest a beneficial pitch of the horizontal spiral-coil type GHE.

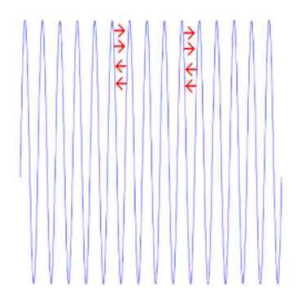

(a) Small pitch

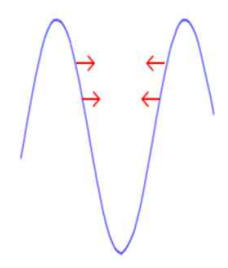

(b) Large pitch

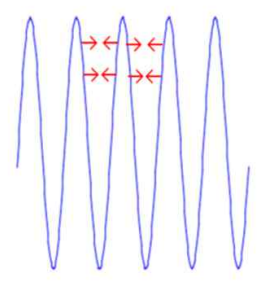

(c) Optimized pitch

Fig. 1 Concept of optimized pitch in horizontal spiral-coil type GHE

\section{Laboratory thermal response test}

\subsection{Description}

Prior to conducting a numerical analysis, a laboratory thermal response test (TRT) was performed to verify the reliability of the numerical analysis. Principle of the laboratory TRT is to monitor the circulating fluid temperatures of the inlet and outlet GHE and to measure the thermal performance of GHE or a nearby ground temperature change. In this study, for comparison of a thermal performance of the GHE, the heat exchange rate of the GHE was calculated by Eq. (1).

$$
\mathrm{Q}=\dot{\mathrm{m}} C_{p} \triangle \mathrm{T}=\dot{\mathrm{m}} C_{p}\left(\mathrm{~T}_{\mathrm{in}}-\mathrm{T}_{\text {out }}\right)
$$

where $\dot{\mathrm{m}}$ refers to the flow rate of the fluid, $C_{p}$ is the specific heat capacity at a constant pressure, $\mathrm{T}_{\mathrm{in}}$ is the inlet temperature of the fluid, and $\mathrm{T}_{\text {out }}$ is the outlet temperature of the fluid.

\subsection{Test prodedure}

The laboratory TRT was conducted with the experimental setup including an electric heater with a circulating pump, a water tank, and a 4-m length spiral-coil shaped polybutylene (PB) heat exchanger. Table 1 show the TRT equipment and specification of the TRT equipment that was used in the test [3]. 
Table 1. Specification of the equipment for TRT

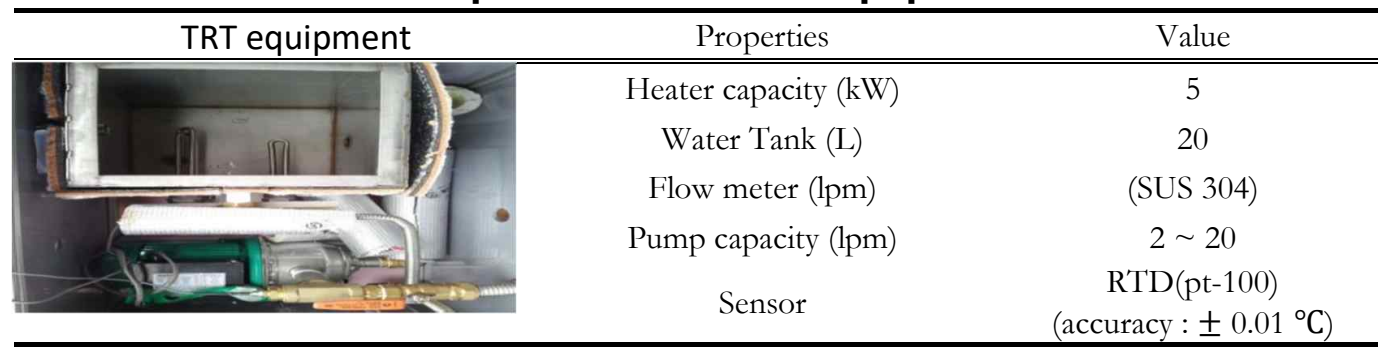

Besides, in the experiment, a $5 \mathrm{~m} \times 1 \mathrm{~m} \times 1 \mathrm{~m}$ steel box filled with dry Joomunjin standard sand (Table 2) was also used to reflect the surrounding ground, while the TRT equipment was installed to supply the circulating water and constant power to the inside of the heat exchanger buried in the ground. The size of the steel box was determined by taking into account the compromise between the sufficiently small to be a lab-scale and large enough for released heat from the GHE not to be disturbed by the end of the box. As the thermal conductivity of the dry Joomunjin standard sand is very low, the volume is large enough for neglecting side effects [4].

Table 2. Properties of standard Joomunjin sand

\begin{tabular}{cc}
\hline Properties & Value \\
\hline \hline Uniformity Coefficient, $\mathrm{C}_{\mathrm{u}}$ & 2.06 \\
Curvature Coefficient, $\mathrm{C}_{\mathrm{c}}$ & 1.05 \\
$\quad$ Specific Gravity, $\mathrm{G}_{\mathrm{s}}$ & 2.65 \\
Maximum Dry Density, & 1617 \\
$\quad \gamma_{\mathrm{dmax}}\left(\mathrm{kg} / \mathrm{m}^{3}\right)$ & 1349 \\
Minimum Dry Density, & 0 \\
$\quad \gamma_{\text {dmim }}\left(\mathrm{kg} / \mathrm{m}^{3}\right)$ & \\
Water Content, $\mathrm{w}(\%)$
\end{tabular}

The outer and inner diameters of the PB pipe were $20 \mathrm{~mm}$ and $16 \mathrm{~mm}$, respectively. In order to measure the temperature change in the surrounding ground, resistance temperature detector (RTD) sensors were installed at $10 \mathrm{~cm}$ away from the edge of the GHE. The initial temperature of the Joomunjin sand was $17.5^{\circ} \mathrm{C}$. The thermal properties of materials and the test procedure are shown in Table 3 and Fig. 2, respectively.

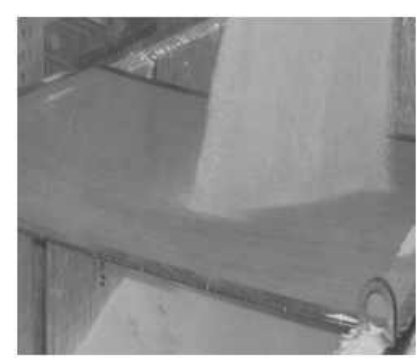

(a) Composition of sample

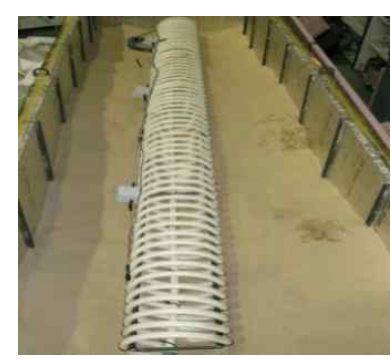

(b) Spiral-coil type GHE setting

Fig. 2 Laboratory TRT process 
Table 3. Thermal properties of experimental material

\begin{tabular}{cccc}
\hline & $\begin{array}{c}\text { Density } \\
\left(\mathrm{kg} / \mathrm{m}^{3}\right)\end{array}$ & $\begin{array}{c}\text { Thermal conductivity } \\
(\mathrm{W} / \mathrm{mk})\end{array}$ & $\begin{array}{c}\text { Specific heat capacity } \\
(\mathrm{J} / \mathrm{kgK})\end{array}$ \\
\hline \hline Soil & 1400 & 0.26 & 807 \\
Circulating water & 1000 & 0.6 & 4200 \\
GHE(PB pipe) & 955 & 0.39 & 525 \\
\hline
\end{tabular}

The laboratory TRT was carried out continuously for 30 hours. In this study, a thermal performance test(TPT) in which the inlet temperature is constant could not be performed using the small-scale steel-box because the thermal conductivity of the sand was so low that the inlet temperature of the circulating water in the TPT could not be constantly maintained. Therefore, the TRTs were conducted with no heat injection, using only the power of the circulating pump, while the heat exchange rates were obtained using Eq. (1) in the same manner as when calculating the heat exchange rate in a TPT. The outlet temperature of the circulating water and the ground temperature change were measured to compare them with the results of numerical analysis.

\section{Numerical study}

\subsection{Description}

To investigate the heat transfer from the fluid flow inside of the GHE, heat exchanges between the soil, pipe and circulating fluid flow should be considered simultaneously in the analysis. In this study, a numerical analysis was conducted using a commercial program known as COMSOL Multiphysics 5.2a, which is based on a finite element method (FEM) [5]. The governing equation of the numerical analysis was based on the heat transfer in the ground as expressed in Eq. (2) [6]. Additionally the heat flow combined with the heat flow through pipe is the energy equation for an incompressible fluid flowing in a pipe as expressed in Eq. (3) [6].

$$
-\lambda_{i}\left(\frac{\partial^{2} T}{\partial x^{2}}+\frac{\partial^{2} T}{\partial y^{2}}+\frac{\partial^{2} T}{\partial z^{2}}\right)+\rho_{i} c_{i} \frac{\partial T}{\partial t}+q_{i}=0 \quad(i=x, y, z)
$$

where $\lambda_{i}$ denotes the thermal conductivity, $T$ is the ground temperature, $\rho_{i}$ is the density, $c_{i}$ is the specific heat capacity and $q_{i}$ is the internal heat generation.

$$
\rho_{f} C_{p} A_{p} \frac{\partial T_{f}}{\partial t}+\rho_{f} C_{p} A_{p} u \cdot \nabla T_{f}=\nabla \cdot A_{p} \lambda_{f} \nabla T_{f}+f_{D} \frac{\rho A_{p}}{2 d_{h}}|u|^{3}+Q+Q_{\text {wall }}
$$

where $\rho_{f}$ denotes the fluid density, $C_{p}$ is the specific heat capacity at a constant pressure, $A_{p}$ is the pipe cross section area, $T_{f}$ is the fluid temperature, $u$ is the tangential velocity of the fluid, and $\lambda_{f}$ is the fluid thermal conductivity. In addition, $f_{D}$ denotes the coefficient of friction, $d_{h}$ is the average hydraulic diameter, and $\mathrm{Q}$ represents the heat injection. Friction loss effects was considered with Churchill's friction model, specification of the GHE (circular, diameter), Reynolds number, and surface roughness. The conduction of the fluid was also considered in the analysis by applying the thermal conductivity of the water. Finally, $Q_{\text {wall }}$ denotes the external heat exchange through the pipe wall which arises from the temperature difference between the pipe wall and the inside of the pipe, and it can be calculated by Eq. (4).

$$
Q_{\text {wall }}=(h Z)_{e f f}\left(T_{p}-T_{f}\right)
$$


where $(h Z)_{\text {eff }}$ represents the effective value of the heat transfer coefficient, $\mathrm{Z}$ is the wall perimeter of the pipe, $T_{p}$ is the temperature at the pipe wall, and $T_{f}$ is the fluid temperature in the pipe. For a circular tube, the effective hZ can be described by Eq. (5).

$$
(h Z)_{\text {eff }}=\frac{2 \pi}{\frac{1}{r_{0} h_{\text {int }}}+\frac{1}{r_{N} h_{\text {ext }}}+\sum_{n=1}^{N}\left(\frac{\ln \frac{r_{n}}{r_{n-1}}}{\lambda_{n}}\right)}
$$

where $\lambda_{n}$ is the thermal conductivity of wall $\mathrm{n}$, and $r_{n}$ is the outer radius of wall $\mathrm{n}$. Furthermore, $h_{\text {int }}$ and $h_{\text {ext }}$ represent the film heat transfer coefficients inside and outside of the tube, respectively. However, in this study, only internal film forced convection was considered in the numerical model because there is no convective heat transfer outside the pipe.

\subsection{Validation}

To verify the reliability of the numerical analysis program, a finite element model was developed under the same conditions as the laboratory test, and then the numerical analysis was performed. The adiabatic conditions were set to the outer edge of the geometry in COMSOL to take into account the side effects. It implies that the initial condition, boundary condition, material properties, geometry and analysis time of the numerical analysis were the same as those in the laboratory TRT. Fig. 3 compares the results of lab test and numerical analysis. In addition, Fig. 4 shows the difference of temperature between COMSOL and the laboratory TRT.

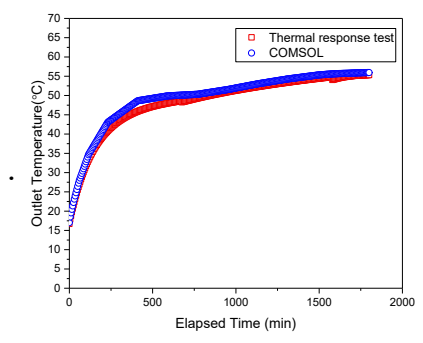

(a) Outlet temperature

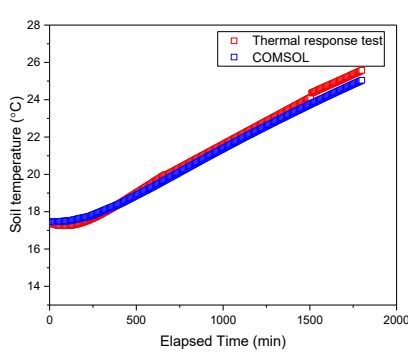

(b) Soil temperature

Fig. 3 Results of lab test and numerical analysis

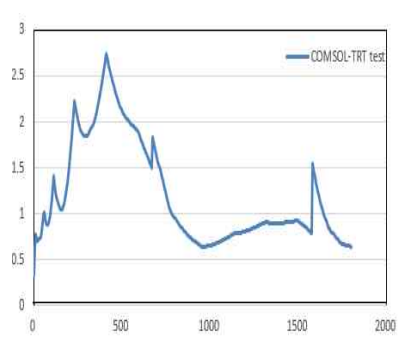

(a) Outlet temperature

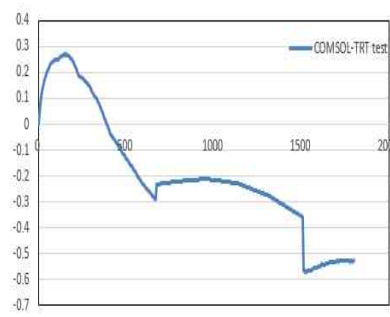

(b) Soil temperature

Fig. 4 Difference of temperature between COMSOL and TRT

As a result of a relative error analysis regarding the laboratory TRT and numerical analysis, the error range of the outlet fluid temperature and soil temperature were $5.9 \%$ and $2.3 \%$, respectively. It can be seen that the numerical 
modelling results validated the agreement with the experimental results.

\subsection{Parametric study}

Prior to a parametric study, installation depth, flow rate and ground thermal conductivity were selected as representative factors which influence the thermal performance of GHE. Table 4 summarizes the case set up for the parametric study.

Table 4. Case set up for parametric study

\begin{tabular}{|c|c|c|c|c|c|}
\hline Case & Installation depth (m) & Flow rate $(1 \mathrm{pm})$ & $\begin{array}{l}\text { Ground thermal conductivity } \\
\qquad(\mathrm{W} / \mathrm{mk})\end{array}$ & \multicolumn{2}{|c|}{$\begin{array}{c}\text { Pitch } \\
\text { (for all cases) }\end{array}$} \\
\hline 1 & 1.8 & 5.65 & 0.8 & \multirow{8}{*}{$\begin{array}{l}0.1 \\
0.2 \\
0.3 \\
0.4 \\
0.5 \\
0.6\end{array}$} & \multirow[b]{2}{*}{0.7} \\
\hline 2 & 1.8 & 5.65 & 1.1 & & \\
\hline 3 & 1.8 & 8.45 & 0.8 & & 0.8 \\
\hline 4 & 1.8 & 8.45 & 1.1 & & 0.9 \\
\hline 5 & 2.5 & 5.65 & 0.8 & & 1.0 \\
\hline 6 & 2.5 & 5.65 & 1.1 & & 1.1 \\
\hline 7 & 2.5 & 8.45 & 0.8 & & 1.2 \\
\hline 8 & 2.5 & 8.45 & 1.1 & & \\
\hline
\end{tabular}

Numerical models were developed to conduct the parametric study. A cooling condition was assumed and analysis time was $120 \mathrm{hr}$, which took into consideration 5 working days per week in the summer. In addition, to consider the actual operation time of the GSHP, operating conditions were set to only operate the heat pump from 9 am to $8 \mathrm{pm}$, the time in which the cooling load occurs during the day. The intermittent operating conditions were described by ceasing the circulating water flow during the rest period, and setting the circulating water flow rate to simulate the operating period (Fig. 5).

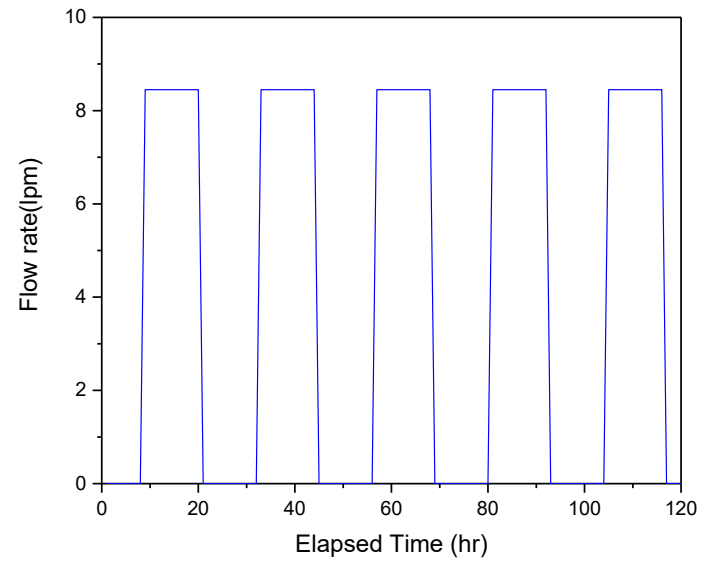

Fig. 5 Boundary condition in the case study

Furthermore, the inlet temperature of the heat exchanger, which is the entering water temperature (EWT) of the system, was set at $35.4^{\circ} \mathrm{C}$. The material of the heat exchanger was PB (Polybutylene), which is commonly used in GHEs, and the outer and inner diameters of the pipe were $20 \mathrm{~mm}$ and $16 \mathrm{~mm}$, respectively. In this study, the total length of the horizontal spiral-coil GHE was kept constant at $40 \mathrm{~m}$ for all cases for comparison of thermal performance. Since the total length of the spiral heat exchanger is constant, a change in pitch or spiral diameter means that the horizontal 
length of the spiral heat exchanger; that is, the required trench length, varies. Then, the numerical analysis was performed for all cases shown in Table 4 when the pitch varies from $0.1,0.2 \cdots$, to $1.2 \mathrm{~m}$. Fig. 6 depicts the finite element model for the case study.

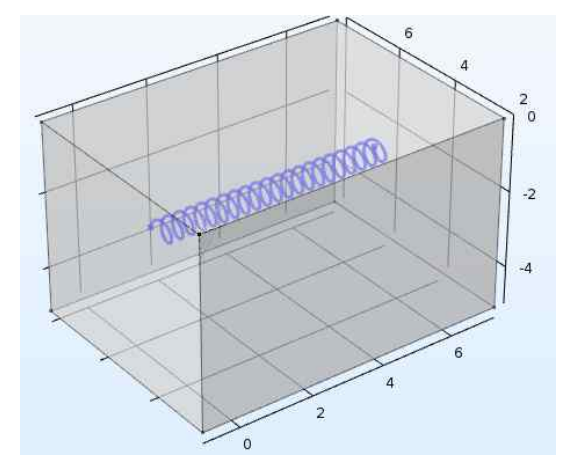

Fig. 6 Finite element model for the case study

\section{Results and discussions}

From the numerical analysis, the heat exchange rate of each case was obtained to compare the thermal performance according to the pitch variation. Fig. 7 compares the heat exchange rates of each case obtained by the parametric study when the pitch is $0.3 \mathrm{~m}$. Fig. 8 indicates a representative result of the parametric study for the outlet fluid temperature.

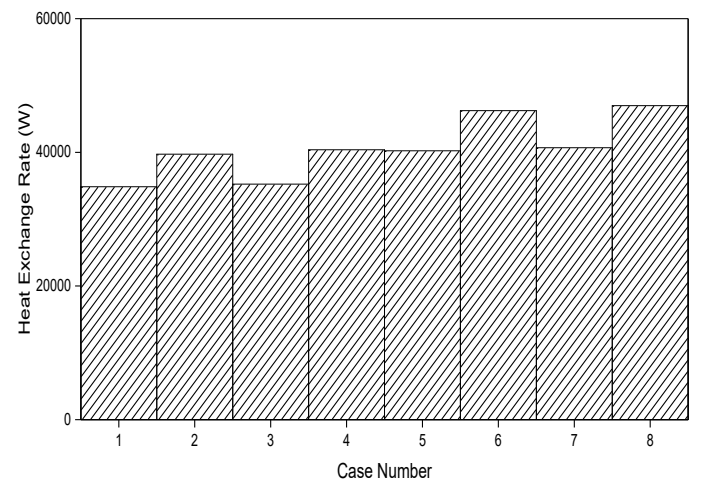

Fig. 7 Heat exchange rate obtained in the numerical study $(p=0.3 \mathrm{~m})$ 


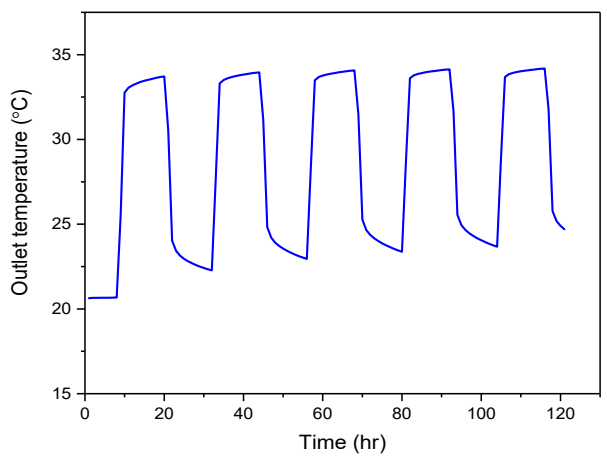

Fig. 8 Variation of outlet temperature in the numerical sudy

Fig. 9 illustrates graphs summarizing the thermal performance evaluation results of case 1 and case 8 according to the pitch variation.

As a result of the thermal performance evaluation according to the pitch variation, it was found that as the pitch becomes larger, the thermal performance gradually increased but it finally converged. As the pitch of the GHE increases, the heat exchange rate gradually increases up until a point where the effects of the pitch value become negligible and the influence of pitch on the heat exchange rate becomes insignificant.

In this work, a T-test with the assumption of equal variance, which is a statistical significance test, was performed to determine the interval in which the pitch value has no further effect on the heat exchange rate. The T-test is a statistical technique which determines whether the difference in the average of two groups is significant, and whether the factor affects the outcome. If the significance probability (P-value) obtained from the T-test results exceeds a significance level of 0.05 , it can be said that there is no statistical significance, and thus it can be concluded that the factor has no effect on the result [7].

As a result of the T-test, it was confirmed that the pitch only had an effect on the heat exchange rate up to a value of $0.6 \mathrm{~m}$ and beyond this value the heat exchange rate was not varied in all cases (Table 5 and Table 6). This finding is observed because increasing the pitch gradually reduces the thermal interference effect between the spirals, until the pitch increases to $0.6 \mathrm{~m}$. However, pitch values greater than $0.6 \mathrm{~m}$ had no effects on the heat exchange rate. The results are consistent regardless of other factors that affect the thermal performance.

Therefore, it can be concluded that when the pitch of the horizontal spiral heat exchanger is set to $0.6 \mathrm{~m}$, an optimal thermal performance can be achieved with the minimal installation site for the horizontal spiral-coil GHE.

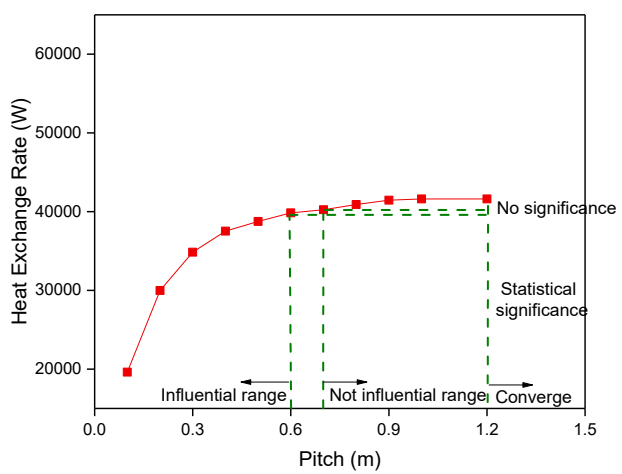

(a) Case 1 


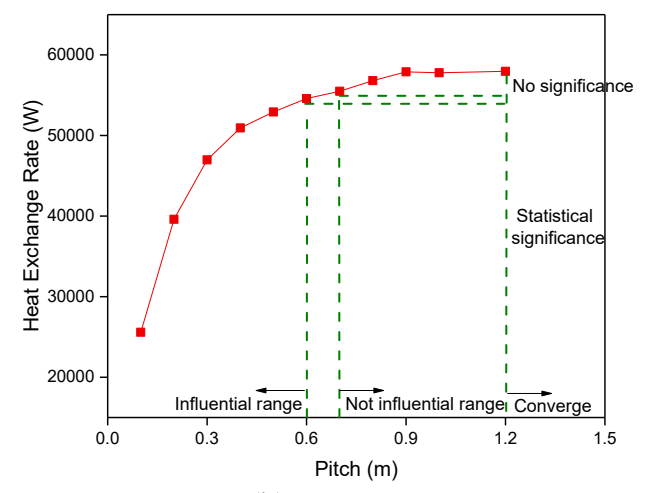

(b) Case 8

Fig. 9 Heat exchange rate according to the pitch variation

(For all cases the pitch vares from $0.1,0.2, \ldots$, to $1.2 \mathrm{~m}$ )

Table 5. Result of a statistical T-test $(p=0.6 \mathrm{~m})$

\begin{tabular}{|c|c|c|c|c|}
\hline & \multicolumn{2}{|c|}{ Levene's Test for Equality of Variances } & \multicolumn{2}{|c|}{ T-test for Equality of Means } \\
\hline & $\mathrm{F}$ & Sig. & Sig. (2-tailed) & Std.Error Difference \\
\hline Equal variances assumed & 0.520 & 0.220 & 0.23 & 8.262 \\
\hline Equal variances not assumed & & & 0.23 & 8.262 \\
\hline & \multicolumn{2}{|c|}{ Levene's Test for Equality of Variances } & \multicolumn{2}{|c|}{ T-test for Equality of Means } \\
\hline & $\mathrm{F}$ & Sig. & Sig. (2-tailed) & Std.Error Difference \\
\hline Equal variances assumed & 0.962 & 0.329 & 0.153 & 17.910 \\
\hline Equal variances not assumed & & & 0.153 & 17.910 \\
\hline
\end{tabular}

\section{CONCLUSION}

In the present study, the thermal performance of horizontal spiral-coil GHEs according to the pitch was investigated. To achieve the goal, a parametric study was conducted using the commercial program COMSOL Multiphysics 5.2a, which is based on a FEM. Prior to a parametric study, the applicability of numerical program was validated by a laboratory TRT result. Then, the parametric study which took into consideration the pitch variation was conducted with regard to the diverse conditions. The conclusion of the study can be summarized as follows:

- Thermal performance of the horizontal spiral-coil GHE continuously increased with increasing pitch, but it was shown that the degree at which performance increases gradually reduces until the heat exchange rate converges.

- A T-test, a statistical significance analysis, was performed to determine a specific pitch value that no longer has an effect on the heat exchange rate, in addition to the results of each parameteric study. As a result, it was concluded that the pitch does not affect the thermal performance if the pitch exceeds $0.6 \mathrm{~m}$. These same results were derived even when additional changes in the critical influence factors were taken into consideration.

\section{ACKNOWLEDGMENTS}

The research was supported by the Regional Development Research Program (17RDRP-B076564-04) by Ministry of Land, Infrastructure and Transport of Korean government and by the basic research project (2018021564) by the 
National Research Foundation of Korea and Ministry of Land, Infrastructure and Transport of Korean government.

\section{REFERENCES}

[1] Conedo, P.M., Conlangeo, G. and Starace, G. 2012. CFD simulations of horizontal ground heat exchangers: A comparison among different configurations, Applied Thermal Engineering, 33-34, 24-32.

[2] Kim, M.J., Lee, S.R., Seok, Y. and Go, G.H. 2016. Thermal performance evaluation and parametric study of a horizontal ground heat exchanger, Geothermics, 60, 134-143.

[3] Yoon, S., Lee, S.R. and Go, G.H. 2015. Evaluation of thermal efficiency in different types of horizontal ground heat exchangers, Energy and Buildings, 105, 100-105.

[4] Yoon, S., Lee, S.R. 2011. Evaluation of heat transfer Characteristics in Soils by Application of Optical Fiber Sensors, Korea Advanced Institute of Science and Technology, MS. Thesis.

[5] Comsol Inc. 2016. Comsol multiphysics user's manual Ver. 5.2a, USA.

[6] Incropera, F.P., Dewitt, D.P., Bergman, T.L. and Lavine A.S. 2007. Fundamentals of Heat and Mass Transfer, (6 $6^{\text {th }}$ Edition), John Willey\&Sons.

[7] Anthony, J.H. (2012) Probability and Statistics for Engineers and Scientists, (4th Edition), Thomson Brooks/Cole. 